\title{
THE CASE FOR CATAPULTS IN THE CLASSROOM: EXPERIENTIAL LEARNING IN MEDIEVAL HISTORY
}

\author{
Jason Hardgrave \\ University of Southern Indiana
}

Students learn what they care about and remember what they understand

-Stanford Ericksen ${ }^{1}$

One must learn by doing the thing, for though you think you know it you have no certainty until you try.

- Sophocles ${ }^{2}$

On what could only be called a blustery day--perhaps appropriate for the activity it was also the first of April--I gathered with ten students to drag four model catapults, three-feet tall and designed to throw tennis balls, onto a practice field at our university. There might have been an inch of water in the grass. The temperature could not have been much more than 45 degrees. We all wore goofy, but duly required hard hats mandated by the university's safety staff. As we worked to dial in the accuracy, twisting and rewinding the skeins on machines to get more power and distance out of them, a few representatives from the press joined us. We spent two hours out there, wet, cold, fighting the wind, and everyone had a smile on their face. What's more, the students' excitement about the catapults was so great that we spent numerous classes talking about it before and afer the event. It became the highlight of their semester, a memorable moment in their college careers, and an infamous episode in our university's history. More important perhaps, it became proof positive of the effectiveness of an experiential learning model in a medieval history class.

\section{Background}

There appears to be a growing interest in community engagement and active learning on today's campuses, but it often seems difficult to discover or create opportunities in liberal arts courses that deviate from the lecture-based and contentdriven model. But who could imagine a science course that followed this pattern? Experience and experimentation have always been hallmarks of the sciences, the scientific method, and the science curriculum. The same experiments have been

\footnotetext{
${ }^{1}$ Stanford C. Ericksen, The Essence of Good Teaching (San Francisco: Jossey-Bass, 1984), 51.
} 
performed countless times in these classes, so what is the purpose in continuing to have students duplicate them? The fundamental aspects and rationale for these laboratory experiments are manifold, but in general it is to assist students in discovering for themselves, and thus enhancing their understanding of, the processes, results, analyses, changes, problem solving, and styles of thinking involved. In such courses these are all deemed necessary parts of the learning process. Similarly, in other higher education and professional degree paths, internships, practicum, and residency programs provide practical and concrete experiences. Doctors and nurses without residency programs? I don't think so. So why should this teaching and learning style be limited to the sciences or to technical and field training? The liberal arts can, and should, effectively employ experiential learning.

Some debate exists over exactly what qualifies as experiential learning. In one definition, experiential learning is learning by doing. This definition encompasses many training exercises that result in the knowledge of how to do a specific task correctly. An alternative, somewhat more complex approach requires the additional elements of reflection and application. Many experiential learning activities encompass both models. One commonly cited and used definition of experiential learning comes from Steve Craig, the Director of the Management Co-op Program at the University of Lethbridge, Alberta, Canada: "Experiential learning is knowledge, skills, and/or abilities attained through observation, simulation, and/or participation that provides depth and meaning to learning by engaging the mind and/or body through activity, reflection, and application." 3

The history and literature on effective teaching and learning styles is extensive. ${ }^{4}$ ${ }^{3}$ Steve Craig, "Experiential Learning Techniques," Management Co-operative Education: Experiential
Learning Research, htpp://people.uleth.ca/ steve.craig/eltech.htm.

${ }^{4}$ The experiential learning movement takes as its founder John Dewey (1859-1952), whose design for education was highly practical. In his 1938 work Experience and Education (New York: Macmillan, 1938), 25, Dewey stated that "all genuine education comes about through experience." His purpose was to prepare students to enter the work force, making them contributors to society, a continual and predominant concern in education today. The other stream of influence on experiential education has come from learning and cognitive psychology, notably through works of Jean Piaget, Benjamin Bloom, and Stanford Ericksen. Jean Piaget (1896-1980) believed education should be child-centered and used to create moral individuals. Piaget's theory illustrates how experience shapes intelligence, and by extension learning and understanding. The Moral Judgment of the Child (New York: Free Press, 1965). Benjamin Bloom (1913-1999) proposed a hierarchy of learning. The potential for engaging all areas in an experiential learning model seems apparent, and many programs have adopted these structures. Benjamin Bloom et al., Taxonomy of educational objectives: Handbook 1, the cognitive domain (New York: David McKay \& Co., 1956). Stanford Ericksen (1911-2000) was also an educational psychologist and the founding director of the Center for Research on Learning and Teaching at the University of Michigan, the first of its kind in the United States. Ericksen's work integrates cognitive development, educational theory, and practical job skills acquisition. This multi-faceted approach required not only 
The most recent champion of experiential learning is David Kolb, whose work provides the connection between theory and practice, demonstrating that learning is a social process based on experiences, a concept challenging many modern teaching strategies. Moreover, Kolb shifts the location of learning away from the classroom and its associated lecture, to diverse locations such as the workplace, the household, the community, and any place people gather for work or play and social interaction.

A topic-specific senior seminar on "Medieval Technology and Culture" provided a unique opportunity to pilot experiential learning models in a liberal arts-based history course. The course explored the relationship between technology and culture in Europe during the Middle Ages (ca. 400-1500 C.E.). In particular, students read a variety of primary and secondary sources, analyzing them to determine the relationships among technology, science, religion, philosophy, politics, economics, geography, and culture.

The objectives for the course included students being able to identify, analyze, use as source material, and correctly cite primary and secondary sources related to the science, technology, and culture of medieval Europe. I also expected students to be able to demonstrate and communicate verbally and in writing their understanding of the following concepts:

- The role and relationship of innovation and diffusion in the transmission of ideas that created, influenced, and shaped medieval technology and culture.

- The complexity of the relationship between technology and culture, particularly in medieval Europe.

- The historical continuity and change related to culture and technology in medieval Europe.

- The intricacy of historical definitions of science, technology, and culture.

- The historiographical trends developed in the study of medieval European science and technology.

These were lofty goals perhaps, but this particular group of seniors was well versed in the general history and literature of the period. Thus, we spent little time covering any generalized background material, leaping straight into the core ideas with classic works such as Lynn White Jr.'s Medieval Technology and Social Change and more recent efforts such as Elspeth Whitney's Medieval Science and Technology. ${ }^{5}$

\footnotetext{
${ }^{4}$ (...continued)

learner-centered curriculum, but faculty willing to attempt diverse teaching strategies including peer mentoring, and tutoring, service learning programs, and internships. - The Essence of Good Teaching (San Francisco: Jossey-Bass, 1984), 198.
}

${ }^{5}$ Lynn White Jr., Medieval Technology and Social Change (London: Oxford University Press, 1966), and Elspeth Whitney, Medieval Science and Technology (Westport, CT: Greenwood Press, 2004). In 
We spent considerable time engaging with course materials and ideas in traditional teaching-and-learning modes of reading, discussing, and writing. But I also welcomed the opportunity to ask students to experiment with various medieval technologies in order to understand them better, and the class seemed excited and intrigued with doing something a bit unusual. The final assignment in the seminar was for each student to determine independently what medieval invention had the greatest impact on the era. After doing extensive research on an invention, each student produced a substantial bibliography of primary and secondary sources, an article-length essay, and a presentation illustrating what he or she believed to be the most important technological achievement of the period and its cultural effects, as well as a justification for the choice.

To be honest, ever since I saw a cow hurtled over the parapet in Monty Python and the Holy Grail and watched an extensive parade of variations on the theme, I had wanted to build a catapult. The complicated aspect of employing experiential learning was to find the time, appropriate opportunities, and best experiments to fulfill the objectives of the course.

\section{Experiential Opportunities}

The beginning of the course was a traditional oral and written analysis and discussion of the writings, but the portion of the class in which we studied medieval technological devices made particularly clear the potential impact of technology on culture. In specific, it occurred to students that measurement in general played a great role in many of the of the other technical achievements of the age. After looking at many navigational devices, students determined that the quadrant was perhaps the most useful of these tools and the basis for many others.

At this point, the course moved into direct experiential learning. I gave each student the materials for constructing a simple quadrant compass. Using a brass brad in the approximate center of a piece of card stock, students used a piece of string tied to the brad and to a pencil, to scribe a circle and then cut it out. They cut the circle in half and folded the remaining half in half again, producing a quarter circle-a quadrant —of double-ply stock. Using the other quarter piece to cut away from the original circle, students folded the card in half a series of times producing angles as a portion of ninety degrees and then transcribed these marks onto their quadrants. Then they attached the piece of string used in making the original circle to the brad ${ }_{i}$ inserted

\footnotetext{
${ }^{5}($...continued $)$

addition to these two books, the students made use of many articles and the texts of Joseph and Frances Gies, Cathedral, Forge, and Waterwheel: Technology and Invention in the Middle Ages (New York: Harper Collins, 1995), Pamela O. Long, Technology and Society in the Medieval Centuries: Byzantium, Islam, and the West, 500-1300 (Washington, D.C.: American Historical Association, 2003), and David C. Lindberg, ed., Science in the Middle Ages (Chicago: University of Chicago Press, 1978).
} 
into the ninety-degree angled corner of the quadrant. Finally, they tied a bead to the end of the string to give it weight and help it hang straight.

Having constructed our measuring devices, the class moved outside to experiment with measuring buildings using a simple triangle formula. Pointing the quadrant at the top of a building, they backed away until the string indicated a 45degree angle on the compass. Then they measured the distance back to the base of the building by pacing it off. In this way, the students could roughly calculate the height of the building, ${ }^{6}$ not a bad project for mostly math-phobic history students. Quadrants were not invented in the Middle Ages but had been used throughout antiquity for astronomy and engineering. These properties led to their use as a maritime navigational aid and the subsequent invention of similar devices in the medieval era such as the backstaff, astrolabe, and sextant. In a comparable way, each theme of the course rapidly became linked intricately with other cultural aspects and technological achievements. In relation to particular themes, the students chose five experiential activities: creating compasses, spinning wool thread, making soap, making quill pens and ink, and building catapults.

By the third set of readings, it was becoming clear that many parts of the technology, economy, and lifestyle of medieval Europe were connected to textiles. Similar to the compass, the process and technology of spinning wool into thread was not a creation of the Middle Ages. The era contributed the spinning wheel, which greatly increased the capacity for producing thread and subsequently cloth. This productivity in turn invigorated the economy, contributed to urban growth, and was even tied to popular rebellions over issues such as enclosure of public lands for sheepraising. The experiential learning pattern that emerged was to find a spinning wheel and get some wool into the hands of the students.

A contact in the National Park Service helped me locate a local person who did spinning and weaving for the Lincoln Boyhood Home, who in turn helped find a contact with the local historical society, who knew a person who did demonstrations for groups and schools using colonial spinning and weaving tools and techniques. Mark Gentry is one of those unique individuals who might have been born in the wrong century. $\mathrm{He}$ likes traditional arts such as candle and soap-making as well as spinning and weaving. As he says it, "I just like to figure out how things were done." He was the perfect fit for our emerging experiential learning philosophy, conceived along the same lines. Mark arrived on campus with a large spinning wheel, known as a walking wheel or a great wheel that was over 100 years old. He also brought along a smaller, foot-powered treadle spinning wheel, combs, cards, and samples of flax, wool, and other natural

\footnotetext{
${ }^{6}$ In fact, as part of the final exam, students were required to measure two buildings on campus with their quadrants. The closer they came to the actual height the more points they received.
}

${ }^{7}$ Mark Gentry, interviewed by author, Evansville, IN, March 18, 2008. 
fibers, as well as skeins of finished thread. We opened the event to the whole campus with an impressive response from a medieval literature class, a couple of art classes, some archaeology students, and various other curious and interested students and faculty.

Through this event, students learned about the qualities of different fibers, the tremendous skill, experience, and amount of time and labor involved in shearing, combing, carding, cleaning, and spinning, and finally weaving wool into a piece of cloth. Back in the classroom, students quickly determined why wool became such an important and profitable business in the Middle Ages and why cloth and clothing so frequently appeared in dowries and bequests from the period. In order to capitalize on this learning experience, we assembled drop spindles from wooden dowels and wooden car wheels purchased at a craft store. The students then attempted to spin some wool into thread. Not surprisingly, the results were poor. In an hour, the longest unbroken thread anyone produced was just short of a yard long. Most of the threads bore a painful resemblance to yarn, thick and with balls and stray fibers sticking out all over. As a result of these brief, active, and fascinating experiences of watching a person use a spinning wheel similar to those invented and used in medieval Europe, and then trying to spin thread as people of the Middle Ages would have before the invention of the spinning wheel, students more thoroughly understood and appreciated the process. Through this activity the students were much more prepared to gauge the cultural impact and implications of the invention of the spinning wheel.

One of the ubiquitous images appearing in medieval manuscripts and other period art is a quill-wielding monk in a scriptorium. The manuscripts themselves are marks of the technological and cultural achievements of the age. Our class was fortunate enough to have an alumnus who collects medieval manuscripts come into class and share representative examples of his collection. He discussed various methods of preparing parchment, ink, and quills and showed examples produced from different combinations of materials and techniques. The students were quite taken with the smell, feel, and beauty of the manuscripts and quickly realized why such works are venerated and prized treasures. Having read about and come in contact with medieval writing, the students were anxious to experience the art of medieval calligraphy for themselves.

We collected goose feathers from around the lake in the middle of campus, and supplemented these with some we purchased at a craft store. Using sharp knives, students fashioned quill pens. Making ink was a bit more problematic, and there was difficulty keeping the pigment suspended. ${ }^{8}$ In the end we used a commercial ink, so the

\footnotetext{
${ }^{8}$ There are many formulae for medieval ink. The general recipe is a mixture of a weak acid, a metallic salt, and a binding agent or gum. Our class used oak gall, vinegar, and Gum Arabic in one test, and commercial iron sulfate, vinegar, and Gum Arabic in another. Both solutions failed to maintain the consistency needed to be used as ink. Subsequent to the course, however, through natural evaporation
} 
students could try out their pens on artificial parchment. Having penned only a few simple lines, the students soon realized that the pen's nib, the ink quality, and the surface of the paper easily could result in smudges, splatters, uneven and unclear writing. As with other experiments, they understood and respected more the artistry and training involved in the production of medieval manuscripts. As one student remarked in the midst of our experiment, "It is amazing at this rate that they wrote anything and that any of it survives at all!"

One additional goal of the seminar was to counter misconceptions about the period and people of the Middle Ages in Europe. Since some of the students were working on Social Science Secondary Education degrees in preparation for becoming high school history teachers, they realized that they might combat the bias against the period, the stereotypical perception of a "dark age," with a few examples from our course. It is a mistaken belief that medieval Europeans didn't bathe, or feared water, or did not have the facilities for simple hygiene. None of these assumptions are generally true and certainly not universal for the period. Further reading led to a midterm project making soap.

Having researched the chemical composition of most medieval soaps, as well as the general procedure, we contacted a woman who makes soap and candles as part of the tour in nearby Historic New Harmony, Indiana. She graciously answered all of our questions and the students went to work. The first process was making an alkaline solution from wood ashes. We burned a pile of scrap oak and placed the ashes in a burlap sack and left it inside a bucket containing water, much like a tea bag steeping in a pot. After a week we removed the liquid and boiled it to reduce the volume until the $\mathrm{pH}$ registered 8.6, indicating a weak alkaline solution. ${ }^{9}$ Rendering of the fat was a much easier project and consisted of various students collecting, melting, and skimming grease from beef and pork. We mixed the potash solution and fats together and stirred over heat until the concoction foamed. The results were unsatisfactory but apparently historically accurate, producing a rather distasteful smelling and feeling off-browncolored jelly. In some ways, it resembled modern soft soap. ${ }^{10}$ Nonetheless, the soap

${ }^{8}($...continued)

and settling, the ink became not only viable but continued to darken and thicken.

\footnotetext{
${ }^{9} \mathrm{We}$ used commercially purchased $\mathrm{pH}$ strips. Two additional, historical, methods were experimented with to check the $\mathrm{pH}$ level, in accordance with our attempt to experience authenticity. One involved putting an egg in the solution unitil a patch of the shell the size of a quarter floated above the surface. The second, absolutely unadvised attempt, was placing a drop of the solution on the tongue, the result was a minor burning sensation indicating the strength of the solution.
}

${ }^{10}$ Out of curiosity and outside of class, ane student-managed to produce some beautiful, modern-looking hard, white bars of soap by using commencial lye, purified lard, and salt. While very satisfying to the

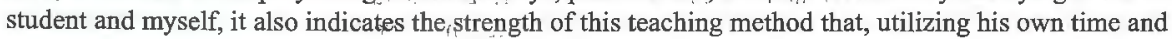


did produce a weak lather in water and appeared to remove oils from the hands. No one was brave enough to bathe with it.

The final activity of the semester was the catapult competition. After a discussion in class, we decided that rather than collaborate on a single catapult, three teams would make models of three different styles of catapults. The parameters of the build were straightforward. ${ }^{11}$ Each student independently researched a type or model of catapult, and then each group chose one model. I approved each, to assure that the three groups were working on different designs and to make sure they had chosen practical designs. ${ }^{12}$ Each group had the same amount of materials-wood, glue, cordage, and leather - and equal access to tools and assigned construction times. The students could use modern tools to construct their models, but the final product could not have any materials deemed unavailable in the Middle Ages. Although iron nails were not unknown in the period, the groups decided that they would have been expensive, difficult to manufacture, and probably impractical in most full-scale catapults. As an alternative, students utilized wooden pegs, glue, and lashings to hold their catapults together. One group took the period materials idea a bit farther. Using a recipe for medieval concrete, they dug a hole in the ground and poured their own counterweights!

The final design included a traction catapult, a tension/torsion catapult, and a counterweight trebuchet. The traction catapult has its origins in China, arriving in the West during the eleventh century. ${ }^{13}$ The design made them portable and effective for throwing small payloads such as incendiaries or diseased human and animal parts over walls. Using a frame to support a balanced throwing arm, the payload is attached to one end and a series of ropes to the other. A group, in concert, pulls on the rope causing the swing arm to launch the ammunition. The traction catapult team had difficulty keeping their model on the ground when they pulled on the launch rope, and due to its size they were unable to get much distance. This machine eventually broke under the strain, losing out on both the distance and accuracy competition. In compensation, however, this model did win the historical and creative design award.

\footnotetext{
${ }^{10}($...continued $)$

expense, a student would go to such trouble.
}

${ }^{11}$ See Appendix A for complete rules on the catapult build and competition.

\footnotetext{
${ }^{12}$ Two of the groups opted for ballista style machines, but these proved to be very difficult to construct with our materials and within our time frame. They shifted to simpler plans of classical tension and torsion design instead.
}

${ }^{13}$ Jieming Liang, Chinese Siege Warfare: Mechanical Artillery \& Siege Weapons for Antiquity (Singapore, Republic of Singapore: Leong Kit Meng, 2006). 
The tension/torsion model was a derivative of a machine employed by the Greeks and Romans, called variously an "onager" and a "mangonel," continuously used throughout the Middle Ages. The source of power, potential energy, comes from the tension of a series of wound cords (a skein) and the torsion of pulling back the swing arm against the grain of the skein. The tighter the cords are wound the farther the machine throws. Needless to say, in the heat of competition the students broke the skein powering their machine by overwinding it and lost the distance competition. They hastily wove a new one before the second, accuracy phase of the competition. Since they did not have to wind the cords as tightly for this contest, they realized that they were much more consistent than the other teams, and they won.

The counterweight trebuchet eventually won the distance competition. These war machines emerged as a consequence of the Crusades, when Western armies encountered stonewalled towns and castles. ${ }^{14}$ While capable of hurling incendiary or biological weapons similar to the other catapults, trebuchets were invented specifically to breach fortified walls. Similar to modern artillery, some medieval trebuchets were capable of moving massive, multi-ton payloads of stone. This team wove a net from cordage to hold their homemade, concrete counterweights of differing sizes. They found the most difficult aspect of the build was constructing and adjusting the payload pouch. Because a trebuchet employs a slingshot-like pouch that gives the ammunition added acceleration, the difficulty is getting the pouch to release at the correct time. Thus, this team's launches far outdistanced the other teams' efforts, winning them that part of the competition, but they failed miserably on accuracy even with a consistent counterweight.

Numerous learning moments came out of this project. In particular, as with previous projects in the class, students gained an appreciation of the skill needed to design and construct these machines. For instance, two students made comments to reporters during the event that were very telling: "It's hard to build a catapult," said one. "The technology is a lot more complicated than people think. The amount of time and effort it took to think something like this up is amazing," commented another student. "There was a lot more technology in the Middle Ages than people give them credit for. ${ }^{.915}$ The students also more clearly understood the chronological development and interdependence of the different designs. It is also significant that these students

\footnotetext{
${ }^{14}$ Brian M. Fagan, The Seventy Great Inventions of the Ancient World (London: Thames \& Hudson, 2004); Bernard S. Bachrach, "Medieval siege warfare: A reconnaissance," The Journal of Military History, 8 (January 1994), 199-134. There have been many television programs on the topic, but one that works quite well in the classroom is "Medieval Siege," Nova: Secrets of Lost Empires II (Arlington, VA: PBS, February 2, 2000), and its accompanying website with teaching resources, http://www.pbs.org/wgbh/nova/lostempires/trebuchet/.
}

${ }^{15}$ Mark Wilson, "Culture of catapulting: Medieval launchers," Evansville Courier Press, April 2, 2008, Local Section. Also available: http:/www.courierpress.com/news/2008/apr/02/culture-of-catapulting/. 
learned to work effectively as a group in a competitive, creative environment, a concept at the heart of experiential learning. ${ }^{16}$ As students had to find their own model, this activity also provided an opportunity to exercise research skills and a practical way to implement them. Finally, the project was enjoyable and engaging: Each student estimated a personal time commitment in researching and building the catapults at an average of thirty hours, and that was time dedicated to the course outside of the classroom! $!^{17}$

\section{Conclusion}

So, after a whole semester of experimenting, both with pedagogy and with medieval technology and models, what is the end result? Unanimously the students in the course indicated three things on their end-of-semester reviews: These experiences had been a tremendous amount of fun and had helped maintain their interest in the overall subject matter; based on these experiences they believed that the people of medieval Europe were adaptable, creative, and resourceful; and, finally, experiential

\footnotetext{
${ }^{16}$ Greg Eckhart and James Kotterman, "Using Toys to Teach Applied Statistics in the Workplace," Michigan Manufacturing Technology Center, SIAM Complexity and Business Analytics Conference, October 10, 2008. Conference Presentations: http://complex.wayne.edu/caba08/CABA08_Kotterman.ppt; "The Statapult (or Catapult) is a Six Sigma and DOE training tool that is used by many companies and universities. We use the Statapult in our courses for team training in applying Experimental Design concepts to real world problems." Launsby Consulting, The Statapult, http://www.launsby.com/Statapult.asp. "Discover new and fun ways to teach experimental design through the use of catapults. Work in groups using catapults in a variety of hands-on lab activiies. See how catapults can help students understand the basic ideas of experimental design by putting them into action. Discuss ways that the underlying lessons can be applied to the real world." Mark G. Haug, "Teaching Basic Experimental Design with Cataults and others Hands-On Activities," The Consortium for the Advancement of Undergraduate Statistics Education, United States Conference on Teaching Statistics, May 19, 2007. http://www.causeweb.org/uscots/uscos07/program/files/breakout3_4.pdf.
}

\footnotetext{
${ }^{17}$ On a personal note, in addition to the enjoyment and insight the students gained, I learned some important lessons about teaching. For example, my seminar was, of course, not the first educational event to use catapults or experiential learning models. In particular, catapults often appear in science classes as models employed to illustrate scientific and mathematical concepts such as motion, energy, velocity, statistics, engineering, and design. See as examples, "Building a catapult: In this lesson for grade seven, students review simple machines and explore how they're used in various careers. Students work in groups to design, construct, and test catapults." Emma Couch and Mitzi Talbert, A lesson plan for grade 7 Science. Learn NC, UNC School of Education. Http://www.learnnc.org/lp/pages/4331, and Lisa Morehouse, "Real Learning Curve: Catapults Demonstrate the Quadratic Equation." What works in Education. http://www.edutopia.org/impact-academy-catapults-quadratic-equation. There appears to have been a series of national high school competitions in the early 1970 s led by teachers of classics and Latin. It drew local media attention, as well as interest from government groups offering assistance. One article noted, "Students find that through this project they are allowed to learn how to learn-not to parrot, but to generate knowledge." Bernard Barcio, "Catapults," The Classical Outlook, 1 (February 1974), 61-62.
} 
learning helped them to understand more clearly and completely the development process and impact of medieval technology.

The course remains the butt of jokes from colleagues and the source of endless inquiries from students wanting to know if and when the infamous catapults course will be taught again. One cannot argue with results like that. Perhaps the perceived absurdity of the experiments will prompt other professors to incorporate some experiential learning into their courses. Maybe it will lessen the instances where I have to tell them just how many inventions of the bad old Middle Ages continue to touch their daily lives. ${ }^{18}$ In all certainty, however, the students had fun and, while that was not the ultimate goal, it captured the attention and enthusiasm of one cohort of students. The course also inspired an interest in the field and period from other students, and even brought media attention to the campus and to medieval history. Who wouldn't be happy with those results? Oh, and I did get to launch a cow from a catapult, even if I was a small, plastic cow.

\section{Appendix: Rules for History 499: Medieval Technology and Culture}

\section{RULES:}

1) All constructions must be based on actual, verified, historical sources (image and/or text) for war machines used in Western Europe in the period 400$1500 \mathrm{CE}$. Teams are allowed to modify and interpret these plans.

2) No modern components will be allowed on any machine.

3) No flammable (gun powder or petroleum products), corrosives, elastic materials, or metal springs may be used in or on the machine.

4) Machines 'must not exceed $3^{\prime}$ in any direction, inclusive of all components at their furthest extent, with the exception of trigger mechanisms, pull lines, and ammo pouches.

5) All machines must be able to accommodate a payload of ammunition equivalent to a tennis ball.

6) Counterweights may not exceed $5 \mathrm{lbs}$. and must be composed of nonbreakable materials (preferably sand, gravel or rocks), and must remain contained within the machine.

7) Trigger or hand firing is acceptable.

8) The base must remain on the ground during firing; no lifting or tipping.

9) Additional materials, beyond those supplied to the team, may be used so long as they have prior approval by he instructor two weeks in advance, do not exceed $\$ 20$ (receipts required), and all other teams are given equal access.

\footnotetext{
${ }^{18}$ Andrew Robinson, “Why Study Medieval History?"- History Review, 39 (March 2001), 47-49.
} 


\section{POINTS and SCORING}

Each team will have three opportunities to launch in each stage of each competition.

Stage 1-Distance:

From a marked point, each team will fire three consecutive payloads of equal mass, in succession.

Distance will be marked from the leading edge of the machine to the point of FIRST impact.

The three distances will be totaled providing an overall score for this stage.

Stage 2-Accuracy:

From a marked point, each team will fire three consecutive volleys at a series of concentric targets $(3,2$, and 1 foot in diameter) fifteen feet from the leading edge of the machine. (Think of a bull's-eye target lying flat on the ground.)

The payload does not have to remain in or on the target, but will be judged on first impact.

Payloads will be awarded points in the following manner; $1^{\prime}=100$ points, $2^{\prime}=50$ points, $3^{\prime}=25$ points.

Combined score for all three shots will be the team's score for the event.

Stage 3-Design:

Based on a group vote from all teams, each model will be evaluated for historic authenticity, accuracy or adherence to historic model and design. They will also take into account creativity, innovative modifications, and the esthetics of the overall design.

\section{Grading for this Assignment:}

(80\%) Individual written submission consisting of:

1) Accuracy, authenticity, and correct citations of source material.

2) An essay of approximately 150 words on why you chose this model.

3) An evaluative narrative of your role in the group.

4) An evaluation of the other members of your group and their roles.

(20\%) Group

1) Accuracy, authenticity, and adaptation of design.

2) Appropriate use of period or equivalent materials.

3) Conformity to the rules.

4) Total combined scores for all events.

5) Creativity, decoration, or thematic additions and modifications. 
Written assignment: In an essay of approximately 150-300 words, describe briefly the history and appeal of your design. Citation to the primary source(s) is required. Images and/or quotes describing your chosen model is recommended. You must create a thesis and support it, about why you chose this model, even if the group chose a different one.

You must then write a brief narrative about what you contributed to the group, related to the assignment of planning, building, and firing a catapult.

You must then write a brief narrative evaluating the role and contributions of everyone else in the group. 